\title{
Genetic diversity analysis of Thai indigenous pig population using microsatellite markers
}

\author{
Rangsun Charoensook ${ }^{1, *}$, Kesinee Gatphayak ${ }^{2}$, Bertram Brenig ${ }^{3}$, and Christoph Knorr ${ }^{4}$
}

* Corresponding Author: Rangsun Charoensook Tel: +66-55-96-2815, Fax: +66-55-96-2704,

E-mail: rangsunc@nu.ac.th

1 Division of Animal Science and Feed Technology, Department of Agricultural Sciences, Faculty of Agriculture Natural Resources and Environment, Naresuan University, Phitsanulok 65000, Thailand 2 Department of Animal and Aquatic Science, Faculty of Agriculture, Chiang Mai University, 50200 Chiang Mai, Thailand

${ }^{3}$ Division of Molecular Biology of Livestock and Molecular Diagnostics, Faculty of Agricultural Sciences, Georg-August University of Göttingen, Göttingen 37077, Germany

${ }^{4}$ Division of Livestock Biotechnology and Reproduction, Faculty of Agricultural Sciences, Georg-August University of Göttingen, Göttingen 37077, Germany

ORCID

Rangsun Charoensook

https://orcid.org/0000-0002-4154-2661

Kesinee Gatphayak

https://orcid.org/0000-0002-5826-8566

Bertram Brenig

https://orcid.org/0000-0002-7635-9656

Christoph Knorr

https://orcid.org/0000-0001-8719-6066

Submitted Nov 2, 2018; Revised Dec 20, 2018 Accepted Feb 16, 2019
Objective: European pigs have been imported to improve the economically important traits of Thai pigs by crossbreeding and was finally completely replaced. Currently Thai indigenous pigs are particularly kept in a small population. Therefore, indigenous pigs risk losing their genetic diversity and identity. Thus, this study was conducted to perform large-scale genetic diversity and phylogenetic analyses on the many pig breeds available in Thailand.

Methods: Genetic diversity and phylogenetics analyses of 222 pigs belonging to Thai native pigs (TNP), Thai wild boars (TWB), European commercial pigs, commercial crossbred pigs, and Chinese indigenous pigs were investigated by genotyping using 26 microsatellite markers.

Results: The results showed that Thai pig populations had a high genetic diversity with mean total and effective $\left(\mathrm{N}_{\mathrm{e}}\right)$ number of alleles of 14.59 and 3.71, respectively, and expected heterozygosity $\left(\mathrm{H}_{\mathrm{e}}\right)$ across loci $(0.710)$. The polymorphic information content per locus ranged between 0.651 and 0.914 leading to an average value above all loci of 0.789 , and private alleles were found in six populations. The higher $\mathrm{H}_{e}$ compared to observed heterozygosity $\left(\mathrm{H}_{\mathrm{o}}\right)$ in TNP, TWB, and the commercial pigs indicated some inbreeding within a population. The Nei's genetic distance, mean $F_{\mathrm{ST}}$ estimates, neighbour-joining tree of populations and individual, as well as multidimensional analysis indicated close genetic relationship between Thai indigenous pigs and some Chinese pigs, and they are distinctly different from European pigs.

Conclusion: Our study reveals a close genetic relationship between TNP and Chinese pigs. The genetic introgression from European breeds is found in some TNP populations, and signs of genetic erosion are shown. Private alleles found in this study should be taken into consideration for the breeding program. The genetic information from this study will be a benefit for both conservation and utilization of Thai pig genetic resources.

Keywords: Genetic Diversity; Microsatellite Markers; Pigs; Phylogenetic Analysis; Thailand

\section{INTRODUCTION}

Native pigs and wild boars are indigenous to Thailand whereas European pigs (e.g. Duroc [DR], Large White [LW], and Pietrain [PT]) were first imported in 1950s [1]. The domestic animal diversity information system (DAD-IS; http://www.dad.fao.org) of the Food and Agriculture Organization (FAO) has listed Thai native pigs (TNP, Sus scrofa) into four breeds, namely Raad (or Kadon), Puang, Hailum and Kwai, according to their physical appearance and the region where they are predominant $[2,3]$. However, these breeds have been classified for some 40 to 50 years, so it is nowadays difficult to determine any unique characteristics which are specific for each pig breed. Moreover, since 1980s native pigs have been increasingly mated with European pigs to improve their economically important traits which eventually led to the development of Thai pork industry. Finally, most native pigs were 
gradually replaced by pure European commercial breeds and have become even less suited for the breeding company's needs, so the number of indigenous pigs in Thailand has steadily decreased over the years [3].

A survey in 1994 [2] reported that less than 500 herdbook native sows and less than 10 nucleus herds were registered. Thai indigenous pigs are nowadays particularly kept in small populations by smallholders in the Northern and NorthEastern provinces of Thailand for reasons of tradition and of religion [3]. However, small pig populations without any scrutinized breeding programs risk to losing their genetic diversity and identity, and becoming extinct. The conservation and utilization of indigenous genetic resources are important to animal sciences. For successful conservation, a detailed knowledge of a breed's phenotypic trait and genetic background are thus very important to study their genetic diversity [4]. Microsatellite markers have been proven to be an extremely powerful tool for analyzing genetic diversity and phylogenetic relationships in animals [e.g. 5-9]. Although numerous reports on foreign pig breeds are available, Thai pig genetics resources are still mostly unknown due to a little study on them [8-10].

Therefore, we performed large-scale genetic diversity and phylogenetic analyses using genomic data on many pig breeds available in Thailand (indigenous, crossbred, commercial exotic breeds, etc.) and Chinese pigs.

\section{MATERIALS AND METHODS}

Research protocols and experimental procedures were approved by the guidelines stated in the Guide for Care and Use of Agricultural Animals in Agricultural Research and Teaching [11].

\section{Resource populations}

Samples of 72 TNPs and 11 Thai wild boars (TWB) were used. Blood, ear clips or hair samples were collected from twelve localities/amphurs of five Northern provinces, namely Mae Hongson (MH), Chiang Mai, Chiang Rai (CR), Uttaradit and Nan. The TNPs consisted of five native pig populations (Table 1). TWBs were considered as one population, as they remained isolated in the wilderness of Chiang Mai and Nan provinces. Three populations of purebred European pigs and two crossbreds between European and Thai pigs were included as well. Collectively, these 11 pig populations were considered as Thai pigs in this study. Additionally, genotypic information on six Chinese breeds were included from our DNA repository in University of Goettingen to compare Thai pigs genetic diversity in reference to Asian pig genetic resources. The Chinese pigs were selected based on different geographical distributions and ecological types reflected by different phenotypic and morphological characters. The Chinese pigs were as follows: Jiangquhai (JQH; lower Yangtze river basin

Table 1. Animals and sampling information

\begin{tabular}{|c|c|c|c|}
\hline Population or breed samples & Sampling location & $\mathrm{N}$ & Type of samples \\
\hline \multicolumn{4}{|l|}{ Thai native pigs (TNP) } \\
\hline Native pig I (MH) & Mae Hongson Province & 6 & Ear clip \\
\hline Native pig II (SCM) & Southern part of Chiang Mai Province & 29 & Blood, ear clip, hair \\
\hline Native pig III (NCM) & Northern part of Chiang Mai Province & 20 & Blood, ear clip \\
\hline Native pig IV (CR) & Chiang Rai Province & 11 & Blood, ear clip \\
\hline Native pig V (UT) & Uttaradit Province & 21 & Blood, ear clip \\
\hline \multicolumn{4}{|l|}{ Thai wild boars } \\
\hline Wild boar (TWB) & Chiang Mai \& Nan Provinces & 11 & Blood, ear clip \\
\hline \multicolumn{4}{|l|}{ Commercial pigs } \\
\hline Duroc (DR) & Chiang Mai Province & 22 & Blood \\
\hline Pietrain (PT) & Chiang Mai Province & 10 & Blood \\
\hline Large White (LW) & Chiang Mai Province & 12 & Blood \\
\hline \multicolumn{4}{|l|}{ Commercial crossbred pigs } \\
\hline Duroc $\times$ native crossbred pig (DXN) & Chiang Mai Province & 10 & Blood \\
\hline Pietrain $\times$ native crossbred pig (PXN) & Chiang Mai Province & 10 & Blood \\
\hline \multicolumn{4}{|l|}{ Chineses indigenous pigs } \\
\hline Jiangquhai (JQH) & Jiangsu Province & 10 & Blood \\
\hline Luchuan (LC) & Guangxi Province & 10 & Blood \\
\hline $\operatorname{Min}(M Z)$ & Liaoning, Jilin \& Heilongjiang Province & 10 & Blood \\
\hline Yushanhei (YJ) & North-Eastern Jiangxi Province & 10 & Blood \\
\hline Tibetan (TI) & Tibet \& Yunan Province & 10 & Blood \\
\hline Rongshang (RC) & Western Sichuan Province & 10 & Blood \\
\hline Total & & 222 & \\
\hline
\end{tabular}

$\mathrm{N}$, number of samples. 
type), Luchuan (LC; South China type), Minpig (MZ; North China type), Rongchang (RC; Southwest China type), Yushanhei (YJ; Central China type), and Tibetan (TI; plateau type) with 10 animals each [12]. Finally, the study analyzed microsatellite markers from a total of 222 pigs.

\section{Molecular genetics analyses}

Genomic DNA was extracted from whole blood ( $9 \mathrm{~mL}$ vials containing ethylenediaminetetraacetic acid) and ear clips by a modified salting out method according to Sambrook et al [13] and Miller et al [14] or from hair roots using the QIAamp DNA mini kit (Qiagen, Germany).

A panel of 26 microsatellites markers covered all porcine chromosomes including the sex chromosomes was analyzed (Table 2, Supplementary Table S1). Primers were fluorescently labelled with dyes FAM or HEX at the 5'-end. Polymerase chain reaction (PCR) assays were performed using 50 to 100 ng of genomic DNA, $2.5 \mathrm{mM} \mathrm{MgCl}, 0.2 \mathrm{mM}$ of each dNTP,
$0.4 \mu \mathrm{M}$ of each primer, and 0.5 units of Taq polymerase (Qiagen, Hilden, Germany) in $1 \times$ PCR buffer as recommended by the manufacturer in a final volume of $25 \mu \mathrm{L}$. The PCR profile consisted of 35 cycles at $94^{\circ} \mathrm{C}$ for $30 \mathrm{~s}$, the specific annealing temperature for $30 \mathrm{~s}$ (see Supplementary Table $\mathrm{S} 1$ ), and an extension period of $30 \mathrm{~s}$ at $72^{\circ} \mathrm{C}$ with an initial denaturation for $2 \mathrm{~min}$ at $94^{\circ} \mathrm{C}$ and a final extension at $72^{\circ} \mathrm{C}$ for $5 \mathrm{~min}$. PCR reactions were performed on a Biometra TGradient thermocycler (Biometra, Goettingen, Germany). To check fragment integrity, PCR products were loaded on $2 \%$ agarose gels.

\section{Genotyping}

For genotyping of samples, the size separation and fragment analysis were performed on an ABI PRISM 3100 DNA analyzer (ABI, Weiterstadt, Germany), using GENESCAN-500ROX as internal size standard according to the manufacturer's specifications. Evaluation of microsatellites and size deter-

Table 2. Characterization of the 26 microsatellites in Thai pigs

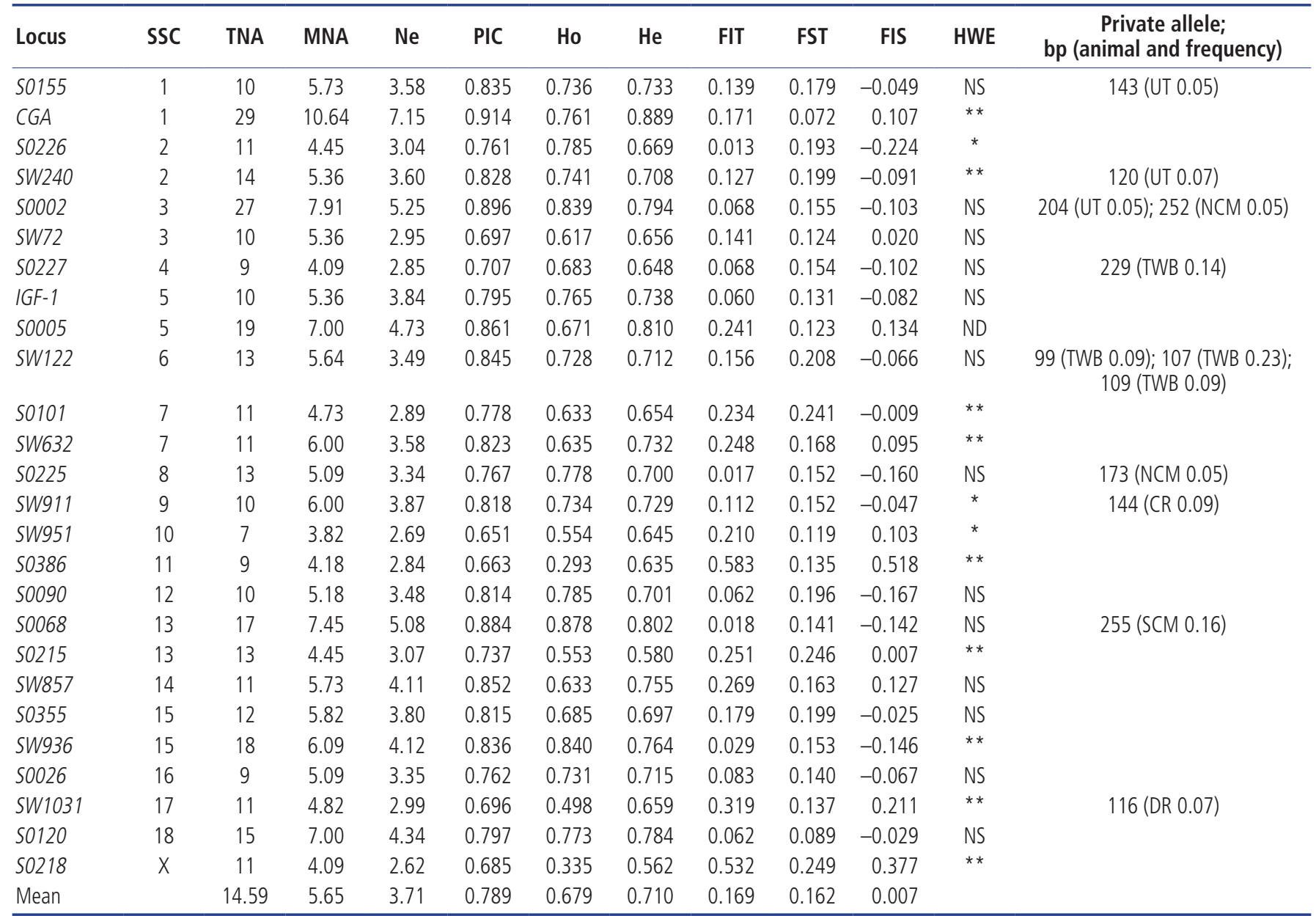

SSC, Sus scrofa chromosome; TNA, total number of alleles per locus; MNA, mean number of alleles per locus; $\mathrm{N}_{\mathrm{e}}$ effective number of alleles per locus; PIC, polymorphism information content, $\mathrm{H}_{0}$ and $\mathrm{H}_{\mathrm{e},}$ the observed and unbiased expected heterozygosity; $F_{T_{T},}$ inbreeding coefficient of an individual relative to the total population; $F_{S_{T},}$ effect of subpopulations compared with the total populations; $F_{15}$ inbreeding coefficient of an individual relative to the subpopulation; HWE, Hardy-Weinberg equilibrium; NS, no significant difference; ND, not done.

${ }^{*} p<0.05 ;{ }^{* *} p<0.01$. 
mination of alleles were done with appropriate ABI-software GENESCAN and Gentoyper software (Applied Biosystems, Waltham, MA, USA), respectively.

\section{Data analyses}

Genetic diversity parameters were estimated for each microsatellite locus and across all loci for each population by the mean number of alleles (MNA), effective number of alleles $\left(\mathrm{N}_{\mathrm{e}}\right)$, observed heterozygosity $\left(\mathrm{H}_{\mathrm{o}}\right)$, expected heterozygosity $\left(\mathrm{H}_{\mathrm{e}}\right)$, and possible deviations from the Hardy-Weinberg equilibrium using GENETIX 4.03 [15] and POPGENE 1.31 [16]. The polymorphism information content (PIC) per locus [17] was calculated by CERVUS 3.0.3 [18]. The inbreeding coefficient of an individual relative to the total population $\left(F_{\mathrm{IT}}\right)$, effect of subpopulations compared with the total populations $\left(F_{\mathrm{ST}}\right)$, and inbreeding coefficient of an individual relative to the subpopulation $\left(F_{\mathrm{IS}}\right)$ and values for each breed were calculated using the FSTAT 2.9.3 [19].

Nei's genetic distance was computed between populations using POPGENE 1.31 [16]. This matrix of genetic distances was used to construct a phylogenetic tree with 1,000 replicates to obtain the corresponding bootstrapping values and to assess the robustness of the dendrogram topology by the neighbour-joining (NJ) method [20] using the PHYLIP package [21]. The dendrogram was depicted using the Tree view software package 1.6.6 [22]. Moreover, the software program GenAlEx 6 [23] was used to conduct two-dimensional data (MDS-2D) based on pair-wise proportion of different alleles, to visualize their similarity or dissimilarity among 17 pig populations. Finally, genetic distances among 222 individuals were estimated as the proportion of shared alleles and represented by a $\mathrm{NJ}$ tree using the molecular evolutionary genetics software version 4.0 [24].

\section{RESULTS AND DISCUSSION}

The ISAG/FAO Standing Committee for biodiversity has recommended a panel of 27 pre-selected porcine microsatellites [25] However, in this present study 24 of the recommended 27 microsatellites were used, because of three markers (S0178, S0228, and SW24) have presented unreliable chromatogramms for fragment analysis. Thus, those markers were replaced by markers S0120 and SW1031 to still cover all porcine chromosomes including the sex chromosomes.

\section{Microsatellite polymorphisms}

In total, 367 alleles were observed at the 26 loci. The total number of alleles per locus varied from 7 (SW951) to 29 (CGA) with a global mean of 14.59 alleles per locus (Table 2). All microsatellites revealed high degrees of polymorphism and allelic diversity. MNA per marker ranged between 3.82 (SW951) and 10.64 (CGA) with an overall mean of 5.65. $\mathrm{N}_{\mathrm{e}}$ ranged between 2.62 (S0218) and 7.15 (CGA) with a pooled mean of 3.71. For nine of the 26 loci private alleles were described. The highest number of specific alleles per marker was visible for SW122 (three). Only for three alleles, frequencies of 10\% or higher were observed (allele 229 at S0227; allele 107 at SW122, and allele 255 at S0068). Genotyping of further individuals should help to verify at the population level which of these alleles are at low frequency or not at all present in the respective pig sources. The highest frequency of specific alleles per population was observed for TWB and pigs collected in the Uttaradit province. Our data support Thuy et al [26] who also reported new alleles per locus present in the indigenous breeds in their comparative study of Vietnamese and European pigs.

The PIC per locus was highest (0.914) for CGA and lowest (0.651) for SW951 leading to an average value above all loci of 0.789 , which is superior to the one of 0.755 of the Thai pigs investigated by 8 and the one of 0.685 reported for Portuguese breeds [6]. The overall $\mathrm{H}_{\mathrm{o}}$ for our Thai pigs was 0.679 and the $\mathrm{H}_{\mathrm{e}}$ was 0.710 . Vincente [6] reported lower values of $0.621 \mathrm{H}_{\mathrm{e}}$ respectively and 0.667 for $\mathrm{H}_{\mathrm{o}}$ respectively. $\mathrm{H}_{\mathrm{e}}$ For Mexican Creole pigs' values of $0.46 \pm 0.04\left(\mathrm{H}_{\mathrm{o}}\right)$ and of $0.72 \pm 0.04$ for $\mathrm{H}_{\mathrm{e}}$ were described [27]. Fabuel et al [28] introduced a $\mathrm{H}_{\mathrm{o}}$ of 0.576 and $a \mathrm{H}_{e}$ of 0.697 calculated for their Iberian pigs. Chaiwatanasin et al [8] documented a mean $\mathrm{H}_{\mathrm{o}}$ of 0.534 and a mean $\mathrm{H}_{e}$ of 0.793 . Wright's $F$-statistic estimates were calculated for each locus (Table 2).

The divergence between $\mathrm{H}_{\mathrm{e}}$ and $\mathrm{H}_{\mathrm{o}}$ for all individuals is expressed as the total inbreeding estimate $\left(F_{\mathrm{IT}}\right)$, with a mean of 0.169 (vary between 0.013 for S0226 and 0.583 for S0386). This value is lower compared to Chinese pigs $[29,30]$ and Portuguese pigs [6]. Our observed $F_{\text {IS }}$ of 0.007 was found to be lower than the those of others (0.274) [30], 0.067 [6], and 0.21 [29]. However, only S0386 (0.518) and S0218 (0.377) were found to be higher than the published data $[29,30]$. The excess of $F_{\mathrm{IS}}$ or the reduction between $\mathrm{H}_{\mathrm{o}}$ and $\mathrm{H}_{\mathrm{e}}$ of microsatellite markers in this study might be caused by null alleles or population subdivisions [31].

The multi-locus $F_{\mathrm{ST}}$ which expresses the population differentiation averages 0.162 . However, the estimated $F_{\mathrm{ST}}$, with respect to a single locus, showed considerable variations in this study i.e., 0.07 in CGA and 0.249 in S0218. This illustrates that only $16 \%$ of genetic variance in our studied populations was explainable by population structures. Thus, in other terms, most genetic variation or diversity was within populations. The comparison of $F_{\mathrm{ST}}$ between our study and the previously published study by Yang et al [30], Li et al [29] and Vicente et al [6] demonstrate that the values were in the same range (0.077 to 0.022$)$.

\section{Genetic diversity in Thai pig populations}

Table 3 depicts the assessment of genetic diversity among Thai 
Table 3. Genetic diversity of local or breed populations

\begin{tabular}{|c|c|c|c|c|c|}
\hline Local or breed population & $\mathrm{MNA} \pm \mathrm{SD}$ & $\mathrm{N}_{\mathrm{e}} \pm \mathrm{SD}$ & $\mathrm{H}_{0} \pm \mathrm{SD}$ & $\mathrm{H}_{\mathrm{e}} \pm \mathrm{SD}$ & $F$ \\
\hline $\mathrm{MH}$ & $4.46 \pm 1.33$ & $3.34 \pm 1.32$ & $0.721 \pm 0.250$ & $0.724 \pm 0.119$ & 0 \\
\hline SCM & $8.23 \pm 2.77$ & $4.50 \pm 1.71$ & $0.638 \pm 0.181$ & $0.754 \pm 0.107$ & 0.139 \\
\hline NCM & $6.15 \pm 1.71$ & $3.90 \pm 1.26$ & $0.726 \pm 0.225$ & $0.731 \pm 0.115$ & 0 \\
\hline$C R$ & $6.15 \pm 2.03$ & $3.99 \pm 1.49$ & $0.638 \pm 0.229$ & $0.746 \pm 0.122$ & 0.105 \\
\hline UT & $7.84 \pm 2.49$ & $5.04 \pm 2.20$ & $0.721 \pm 0.164$ & $0.792 \pm 0.079$ & 0.066 \\
\hline TWB & $6.15 \pm 1.28$ & $4.28 \pm 1.29$ & $0.671 \pm 0.214$ & $0.782 \pm 0.081$ & 0.100 \\
\hline DR & $5.53 \pm 2.46$ & $3.23 \pm 1.59$ & $0.627 \pm 0.217$ & $0.641 \pm 0.175$ & 0 \\
\hline PT & $4.50 \pm 1.83$ & $3.03 \pm 1.41$ & $0.574 \pm 0.225$ & $0.630 \pm 0.186$ & 0.017 \\
\hline LW & $4.26 \pm 1.11$ & $2.84 \pm 0.98$ & $0.589 \pm 0.181$ & $0.632 \pm 0.170$ & 0.047 \\
\hline DXN & $4.07 \pm 1.87$ & $3.24 \pm 1.35$ & $0.853 \pm 0.256$ & $0.685 \pm 0.121$ & 0 \\
\hline PXN & $4.96 \pm 1.79$ & $3.46 \pm 1.12$ & $0.712 \pm 0.240$ & $0.710 \pm 0.131$ & 0 \\
\hline
\end{tabular}

MNA, mean number of alleles per locus; $N_{e}$ effective number of alleles per locus; $H_{0}$ and $H_{e}$, the observed and unbiased expected heterozygosity; $F$, heterozygote deficiency or inbreeding coefficient.

MH, Mae Hongson; SCM, Southern part of Chiang Mai; NCM, Northern part of Chiang Mai; CR, Chiang Rai; UT, Uttaradit; TWB, Thai wild boars; DR, Duroc; PT, Pietrain; LW, Large White; DXN, Duroc $\times$ native crossbred pig; PXN, Pietrain $\times$ native crossbred pig.

pig populations. Over all, mean MNA and $\mathrm{N}_{\mathrm{e}}$ were high in Thai native pigs (TNP) and TWB. Only pigs from $\mathrm{MH}$ revealed fewer superior values where both MNA and Ne were comparatively lower than some of the commercial pigs and crossbreds. A higher allelic diversity in indigenous breeds is known [26] and probably the consequence of the lack of planned mating programmes. The higher $\mathrm{H}_{\mathrm{e}}$ compared to $\mathrm{H}_{\mathrm{o}}$ in TNP, TWB, and the commercial pigs indicated some inbreeding within population but opposed to the crossbred pigs that revealed a surplus of heterozygous animals $\left(\mathrm{H}_{0}>\mathrm{H}_{\mathrm{e}}\right)$. A high heterozygosity must be attributed to heterosis, and at the same time to a marginal degree of inbreeding effects. In their earlier study, Chaiwatanasin et al [8] described estimates for $\mathrm{H}_{\mathrm{e}}$ and $\mathrm{H}_{\mathrm{o}}$ in TNP and commercial Thai pigs represented by the breeds LW, PT, and Spotted Large White (SLW). Their report stated small $\mathrm{H}_{\mathrm{o}}$ differences between populations only. It was, however, unexpected that their estimates for $\mathrm{H}_{\mathrm{o}}$ in LW and SLW but PT were higher as compared to TNP. The highest $\mathrm{H}_{\mathrm{e}}$ was computed for TNP. Pigs in [8] revealed a larger ratio of $\mathrm{H}_{\mathrm{e}}$ and $\mathrm{H}_{\mathrm{o}}(0.534$ and 0.793$)$ due to smaller $\mathrm{H}_{\mathrm{o}}$ compared to pigs in this study. However, we could not verify our results with them as their animals' detailed origin information was unavailable [8].

Most inbreeding coefficients $(F)$ in this study were either zero (crossbreds) or small (commercial breeds) (Table 3). No inbreeding or excess heterozygosity in crossbreds could be largely due to the presence of heterosis. However, the low or negligible $F$ in commercial pigs could be caused by the sophistication of the breeding programs [3,8,9]. However, some inbreeding signs were found in pigs from southern part of Chiang Mai Province (SCM; 0.139), Chiang Rai Province (CR; 0.105) and the TWB (0.100). It is assumed that inbreeding between closer relatives might have occurred. For example, in a non-inbred population, a $F$ of at least 0.125 is expected to occur if either grand-father/grand-daughter (grand-mother/ grand-son), alternatively half-brother/half-sister or uncle/ niece (aunt/nephew) are mated. We cannot rule these scenarios out as animals of these populations were kept in small villages for generations (SCM and CR) or were caught and kept in captivity as it was in the case of the TWB.

\section{Genetic distances and phylogenetic relationships between pig populations}

Genetic distances for the Thai and Chinese pig populations (JQH, LC, MZ, YJ, TI, and RC; Table 1) were assessed according to Nei [32] and by mean $F_{\mathrm{ST}}$ estimates (significance was tested using the permutation test). Pair-wise comparisons for all pig populations are shown in Table 4. Nei's estimates indicated a higher than expected genetic distance between TWB and TNPs (from 0.352 to 0.606 ). It was interesting that the genetic distance among TWB and DR and PT ( 0.579 and $0.567)$ was even lower than the one to MH (0.606). However, expectedly, those of crossbreds estimates were somewhere in between the 'founder' breeds. Larger genetic distances $(\geq 0.439$, expect for TI to RC) were also found between those of Chinese breeds, especially between LC and JQH (0.741). We also observed greater genetic distances between Thai and Chinese pigs. The closest relationships were, however, estimated between the Chinese breeds (TI and RC), and between TNP populations (SCM and CR). For TWB, its closest neighbour among the Chinese breeds was TI $\left(F_{\mathrm{ST}}: 0.082\right)$. This situation might be possible that TI pigs have domesticated from wild boars in the near past with least breeding and selection by human.

The overall $F_{\mathrm{ST}}$ of 0.162 indicates significant population subdivision in the studied Thai pig breeds. Laval et al [33] reported higher estimates for European breeds $\left(F_{\mathrm{ST}}=0.27\right)$. Lower values $F_{\mathrm{ST}}$ were also reported in Chinese breeds $(0.077)$ [30]. Our pair-wise $F_{\mathrm{ST}}$ estimates ranged from 0.037 (between CR and SCM) to 0.235 (between LW and LC). These esti- 
Table 4. The Nei's (1972) standard genetic distance (below diagonal) and mean $F_{S T}$ estimates (above diagonal) among each pair of 17 populations

\begin{tabular}{|c|c|c|c|c|c|c|c|c|c|c|c|c|c|c|c|c|c|}
\hline Population & $\mathrm{MH}$ & SCM & $\mathrm{CM}$ & CR & UT & WB & DR & LW & PT & XN & PXN & $\mathrm{QH}$ & LC & $\mathrm{MZ}$ & YJ & $\mathrm{TI}$ & $\mathrm{RC}$ \\
\hline $\mathrm{MH}$ & - & 075 & 091 & 089 & 079 & 126 & 47 & 158 & 47 & 108 & 122 & 37 & 179 & 156 & 142 & 01 & .113 \\
\hline CM & 287 & . & 054 & 037 & 039 & & & & & & & & & & & & \\
\hline CM & 354 & .261 & 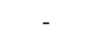 & 0.068 & 0.055 & & 0.091 & & 0.097 & & & & & & & 92 & 0.098 \\
\hline$C R$ & 312 & 127 & 300 & - & 0.046 & 0.085 & 0.107 & .118 & 0.103 & 095 & 086 & 60 & 0.129 & & 122 & 86 & 0.093 \\
\hline JT & & 177 & & .184 & - & 0.063 & 0.088 & 0.103 & 0.086 & & 0.069 & & & & & & 0.075 \\
\hline TWB & & & & 1723 & & 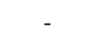 & & & & & & & & & & & 0.102 \\
\hline$R$ & 558 & 51 & 54 & 0.418 & 0.371 & 0.579 & - & 0.082 & 0.064 & 095 & 0.111 & 99 & 0.199 & & 0.183 & 0.131 & 0.149 \\
\hline W & & 20 & 33 & .399 & 0.380 & 0.619 & .233 & - & 0.067 & 39 & 12 & & 0.235 & & 90 & 52 & 0.165 \\
\hline & & & & & & & & & 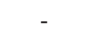 & & & & & & & & 0.146 \\
\hline 政 & 然 & & 0 & 0.383 & 0.319 & 0.526 & 0.317 & 0.448 & 0.318 & - & 0.114 & & 0.182 & & & & 0.130 \\
\hline XN & 474 & 369 & 358 & 0.353 & 0.305 & 0.520 & 0.407 & 0.335 & 0.408 & .450 & . & 0.182 & 0.166 & & 0.148 & 03 & 0.118 \\
\hline JQH & 459 & 0.588 & 0.474 & 0.629 & 0.532 & 0.702 & 0.712 & 0.719 & 0.735 & 0.534 & 0.686 & - & 0.222 & 90 & 0.187 & & 0.147 \\
\hline LC & 0.615 & 0.420 & 0.619 & 0.468 & 0.452 & 0.542 & 0.702 & 0.771 & 0.742 & 0.663 & 0.604 & & . & 0.216 & 0.171 & 0.114 & 0.134 \\
\hline MZ & & & & 0.518 & 0.486 & 0.659 & 0.627 & & 0.533 & & & & & - & 0.158 & 0.125 & 0.146 \\
\hline YJ & 0.523 & 0.471 & 0.559 & 0.492 & 0.416 & 0.611 & 0.702 & 0.657 & 0.691 & 0.592 & 0.607 & 0.659 & 0.584 & 0.566 & - & 0.101 & 0.111 \\
\hline $\mathrm{TI}$ & 0.462 & 0.350 & 0.524 & 0.456 & 0.369 & 0.484 & 0.646 & 0.665 & 0.628 & 0.567 & 0.519 & 0.579 & 0.431 & 0.582 & 0.442 & - & 0.055 \\
\hline $\mathrm{RC}$ & 0.456 & 0.359 & 0.480 & 0.421 & 0.392 & 0.543 & 0.648 & 0.643 & 0.631 & 0.581 & 0.534 & 0.557 & 0.489 & 0.618 & 0.435 & 0.216 & - \\
\hline
\end{tabular}

MH, Mae Hongson; SCM, Southern part of Chiang Mai; NCM, Northern part of Chiang Mai; CR, Chiang Rai; UT, Uttaradit; TWB, Thai wild boars; DR, Duroc; LW, Large White; PT, Pietrain; DXN, Duroc $\times$ native crossbred pig; PXN, Pietrain $\times$ native crossbred pig; JQH, Jiangquhai; LC, Luchuan; MZ, Min; YJ, Yushanhei; TI, Tibetan; RC, Rongshang.

mated were within the ranges from various early reports such as reports using microsatellite markers in European breeds $(0.11$ to 0.27$)[6,33,34]$ or reports in Chinese and Korean breeds $(0.18$ to 0.26$)[5,29,35]$. The wider range of $F_{\mathrm{ST}}$ estimates between of TNP and European breeds also coincided with those reported by Chaiwatanasin et al [8]. On the con- trary to that TWB are genetically more distant to European pigs. Note that the existing disagreements among reports are probably due to distinctive marker sets and quality of animal samples i.e. randomly sampled [5] or not.

A phylogenetic tree consisting of the 17 populations was reconstructed based on Nei's genetic distances (Table 1, Figure

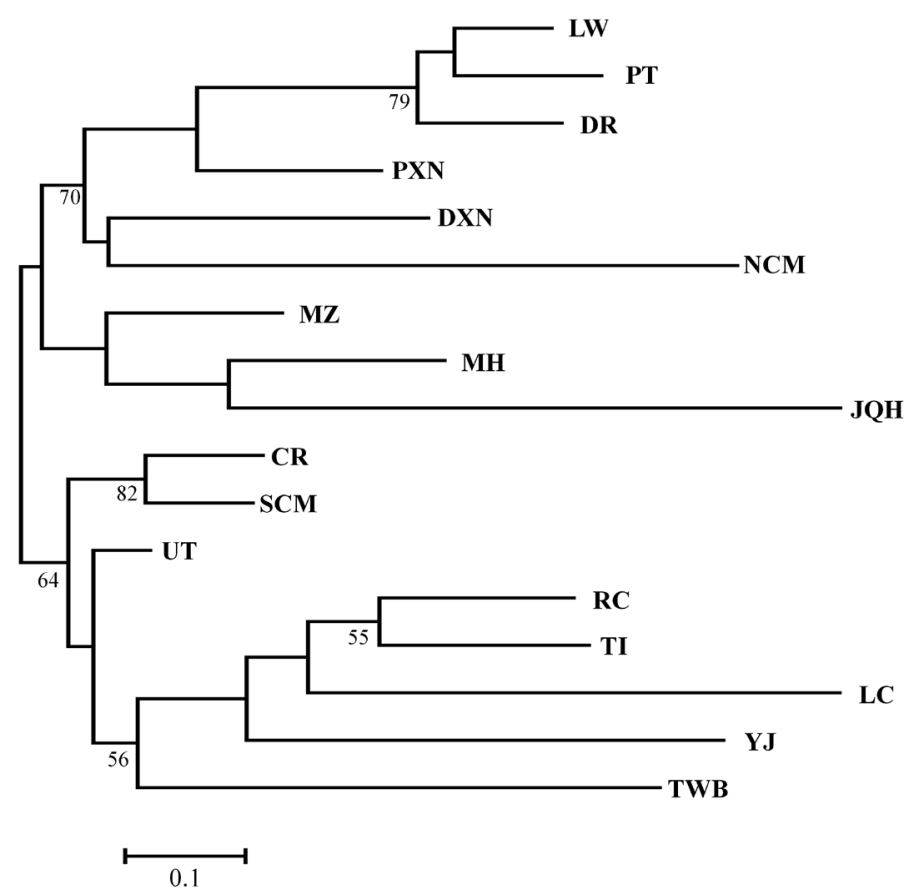

Figure 1. Representation of neighbour-joining Nei's (1972) standard genetic distance among Thai and Chinese pig populations, based on 1,000 replicates (numbers in nodes are percentage bootstrap values). LW, Large White; PT, Pietrain; DR, Duroc; PXN, Pietrain $\times$ native crossbred pig; DXN, Duroc $\times$ native crossbred pig; NCM, Northern part of Chiang Mai; MZ, Min; MH, Mae Hongson; JQH, Jiangquhai; CR, Chiang Rai; SCM, Southern part of Chiang Mai; UT, Uttaradit; RC, Rongshang; TI, Tibetan; LC, Luchuan; YJ, Yushanhei; TWB, Thai wild boars. 
1) [36], and the tree could be distinguished into two distinct clusters. The first cluster consisted of three commercial breeds, all crossbred pigs, two TNPs (Northern part of Chiang Mai Province $[\mathrm{NCM}]$ and $\mathrm{MH}$ ) and two Chinese populations (MZ and JQH). The additional Chinese breeds arranged with TWB and three TNPs (CR, SCM, and UT) and formed the second cluster. The phylogenetic tree infers a close relationship between Thai native and Chinese pigs. At the same time both populations are distinctly different from European lineages.

Multidimensional scaling (MDS) in a two-dimensional area (Figure 2) was further computed to display genetic similarities among populations based on the pair-wise proportion of different alleles $\left(F_{\mathrm{ST}}\right)$. The MDS showed that European pigs separated clearly from each other, the crossbreds and the NCM populations formed a second group, which separated Asian pigs from European pigs. This indicated that crossbreeding events with individuals on commercial farms might have occurred in NCM population.
To analyse the genetic admixture in each pig population, NJ tree of individuals was constructed based on Nei's unbiased genetic distance [36] of the shared allele proportions (Figure 3). The genetic differentiation among different pig breeds or populations was probably due to selection, genetic drift, and local inbreeding effects. On the other hand, the close genetic relationship between some TNPs and the crossbreds could be a direct effect of a genetic introgression from European pigs. In 1957, the Department of Livestock Development at the Ministry of Agriculture, under the guidance of FAO, started to import European pig breeds into Thailand and has promoted for the production of crossbred pigs for sale in local areas [2].

\section{Implications of Thai pig genetic resources}

The term "livestock genetic resources" has included all livestock species, breeds and strains that are of economic, scientific and cultural interest to humankind in terms of sustainable food and agricultural production [3]. Accordingly, TNPs are

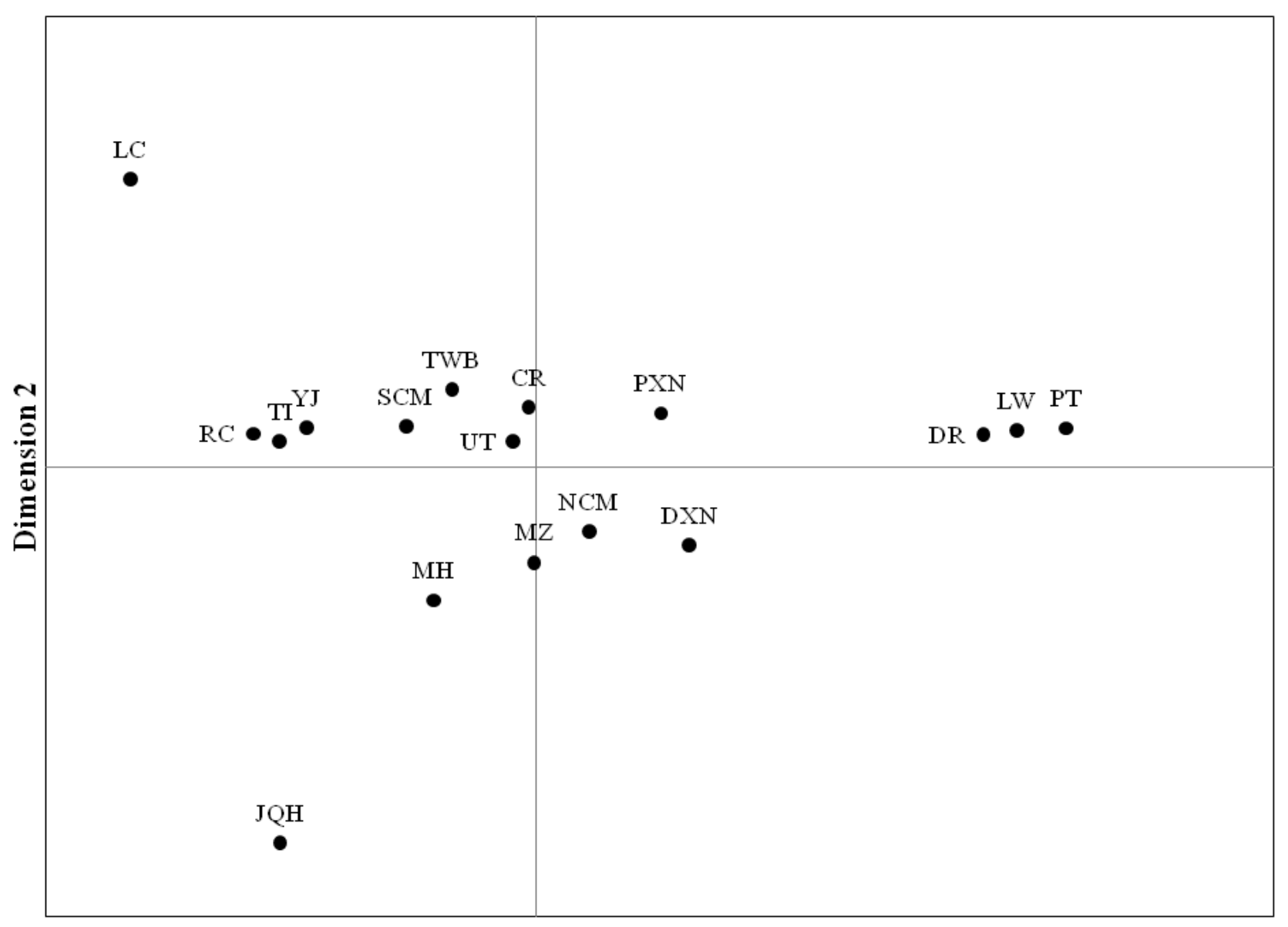

Dimension 1

Figure 2. Multi-dimensional scaling (MDS) in a two-dimensional area based on pair-wise proportion of different alleles $\left(F_{\mathrm{ST}}\right)$ among 17 pig populations. Axis1 $=43.21 \%$, Axis2 = 25.22\%. See Table 1 for population abbreviations. LC, Luchuan; RC, Rongshang; TI, Tibetan; YJ, Yushanhei; SCM, Southern part of Chiang Mai; TWB, Thai wild boars; CR, Chiang Rai; UT, Uttaradit; PXN, Pietrain $\times$ native crossbred pig; DR, Duroc; LW, Large White; PT, Pietrain; NCM, Northern part of Chiang Mai; DXN, Durocxnative crossbred pig; MZ, Min; MH, Mae Hongson; JQH, Jiangquhai. 


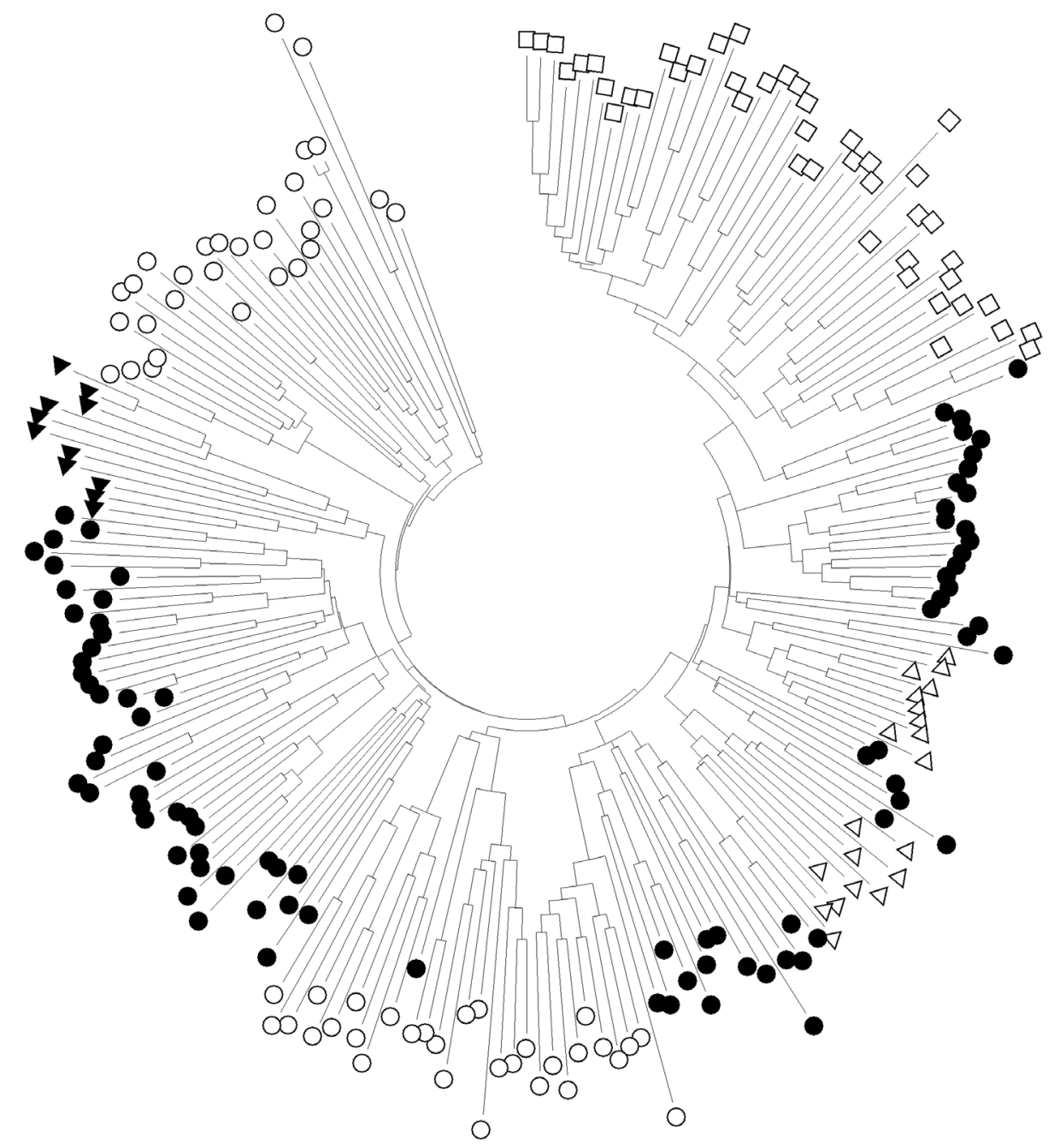

Figure 3. Neighbour-joining tree based on the proportion of shared alleles of Thai native pigs (black circle), Thai wild boars (black triangle), Commercial crossbred pigs (white triangle), Commercial pigs (white square), and Chinese pigs (white circle).

well adapted to hot and humid climates, tolerate to low quality of feed stuff, and probably are better resistant to internal parasites and viral diseases [2]. Moreover, some study has reported that 24 TNPs in Lamphun province remained healthy with complete protection and no symptoms while the foot and mouth virus attacked all cattle of the village. This showed that TNPs could resist the virus which was confirmed by a low antibody titre (less than 40\%) [37]. Thus, it seems likely that Thai indigenous pigs might be a useful genetic resource.

The primary focus of our study was to evaluate the genetic background of pigs in Northern Thailand that are the main genetic resource of native pigs in this country. Our previous study had described specific mtDNA signatures for TNPs and TWBs [10]. In this present study, the private microsatellite alleles which are recommended to be conserved in populations are found here for UT (S0155, SW240, S0002), NCM (S0002, S0225), TWB (S0227, SW122), CR (SW911), SCM (S0068), and DR (SW1031) and will provide additional in- formation to genetically describe the uniqueness of TNPs and TWB. It should therefore be a benefit for both conservation purposes as well as to utilizing them for a sustainable pig production. However, since the knowledge of indigenous pig genetics is still limited, a further collaboration among the agencies within and between countries is required [3].

In conclusion, microsatellite loci analyses indicated close genetic relationship between Thai indigenous and Chinese pigs. NCM pig population showed a genetic introgression from European breeds, and some Thai indigenous pigs (SCM, $\mathrm{CR}, \mathrm{TWB})$ showed signs of genetic erosion. It could be assumed that genetic diversity of Thai indigenous pigs is a product of different husbandry systems and lack of suitable breeding programs. Urgent measures of conservation and sustainable management of their gene pool must be undertaken, and private alleles which found in this study should be taken into consideration for the breeding program. 


\section{CONFLICT OF INTEREST}

We certify that there is no conflict of interest with any financial organization regarding the material discussed in the manuscript.

\section{ACKNOWLEDGMENTS}

This work was supported by a grant of the Erxleben Research and Innovation Council to Bertram Brenig (ERIC-BR19592005-1). Rangsun Charoensook was awarded a fellowship from Katholischer Akademischer Ausländer-Dienst (KAAD), Germany.

\section{REFERENCES}

1. Visitpanich T, Falvey L. A survey of highland pig industry. Thai J Agric Sci 1980;13:259-67.

2. Rattanaronchart S. Present situation of Thai native pigs. Chiang Mai, Thailand: Scientific Report of the Department of Animal Science, Faculty of Agriculture, Chiang Mai University; 1994.

3. Charoensook R, Knorr C, Brenig B, et al. Thai pig and cattle production, genetic diversity of livestock and strategies for preserving animal genetic resources. Maejo Int Sci Technol 2013;7:113-32.

4. Rege JEO, Okeyo AM. Improving our knowledge of tropical indigenous animal genetic resources. Animal Genetics Training Resource, CD Version 2. Nairobi, Kenya: International Livestock Research Institute (ILRI); 2006.

5. Kim TH, Kim K, Choi BH, et al. Genetic structure of pig breeds from Korea and China using microsatellite loci analysis. J Anim Sci 2005;83:2255-63. https://doi.org/10.2527/2005.8310 2255x

6. Vicente AA, Carolino MI, Sousa MCO, et al. Genetic diversity in native and commercial breeds of pigs in Portugal assessed by microsatellites. J Anim Sci 2008;86:2496-507. https://doi. org/10.2527/jas.2007-0691

7. Fang $\mathrm{M}, \mathrm{Hu} \mathrm{X}$, Jin $\mathrm{W}$, et al. Genetic uniqueness of Chinese village pig populations inferred from microsatellite markers. J Anim Sci 2009;87:3445-50. https://doi.org/10.2527/jas.20081632

8. Chaiwatanasin W, Chantsawang S, Tabchareon S. Genetic diversity of four pig breeds in Thailand based on microsatellite analysis. Kasetsart J (Nat Sci) 2002;36:248-52.

9. Charoensook R, Brenig B, Gatphayak K, Knorr C. Genetic identity of native pig breeds in northern Thailand evidenced by microsatellite markers. Proceeding of Tropentag 2009, International Conference on Research for Development in Agriculture and Forestry, Food and Natural Resource Management. Hamburg, Germany: University of Hamburg; 2009.

10. Charoensook R, Brenig B, Gatphayak K, Knorr C. Further resolution of porcine phylogeny in Southeast Asia by Thai
mtDNA haplotypes. Anim Genet 2011;42:445-50. https:// doi.org/10.1111/j.1365-2052.2011.02175.x

11.FASS. Guide for the care and use of agricultural animals in agricultural research and teaching. 1st ed. Savoy, IL, USA: Federation of Animal Science Societies; 1999.

12. Chen K, Knorr C, Bornemann-Kolatzki K, et al. Targeted oligonucleotide-mediated microsatellite identification (TOMMI) from large-insert library clones. BMC Genet 2005;6:54. https:// doi.org/10.1186/1471-2156-6-54

13. Sambrook J, Frisch EF, Maniatis T. Molecular Cloning: a laboratory manual. 2nd ed. New York, USA: Cold Spring Harbor Laboratory Press; 1989.

14. Miller SA, Dykes DD, Polesky HF. A simple salting out procedure for extracting DNA from human nucleated cells. Nucleic Acids Res 1988;16:1215. https://doi.org/10.1093/nar/ 16.3.1215

15. Belkhir K, Borsa P, Goudet J, et al. Genetix, Windows ${ }^{\mathrm{TM}}$ software for population genetics. CNRS UPR 9060. Montpellier, France: Genome and Populations Laboratory, University of Montpellier.

16. Yeh FC, Yang R, Bozle T. POPGENE Version 1.31, MS Windows-based freeware for population genetic analysis. Edmonton, $A B$, Canada: University of Alberta and Center for International Forestry Research; 1999.

17. Botstein D, White RL, Skolmick H, Davis RW. Construction of a genetic linkage map in man using restriction fragment length polymorphism. Am J Hum Genet 1980;32:314-31.

18. Marshall TC, Slate J, Kruuk LEB, Pemberton JM. Statistical confidence for likelihood-based paternity inference in natural populations. Mol Ecol 1998;7:639-55.

19. Goudet J. FSTAT, a program to estimate and test gene diversities and fixation indices 2001; (version 2.9.3). [2017 Oct 27]. Available from: https://www2.unil.ch/popgen/softwares/fstat. htm

20. Saitou N, Nei M. The neighbor-joining method: a new method for reconstructing phylogenetic trees. Mol Biol Evol 1987;4:40625. https://doi.org/10.1093/oxfordjournals.molbev.a040454

21. Felsenstein J. Phylogeny Inference Package (PHYLIP). Seattle, WA, USA: Genomes Sciences, Department of Genetics, University of Washington; 1993-2002. Available from: http:// evolution.gs.washington.edu/phylip.html

22. Page RDM. TREEVIEW: An application to display phylogenetic trees on personal computers. Comput Appl Biosci 1996;12:357-8.

23. Peakall R, Smouse PE. GENEALEX 6: genetic analysis in Excel. Population genetic software for teaching and research. Mol Ecol Notes 2006;6:288-95. https://doi.org/10.1111/j.14718286.2005.01155.x

24. Tamura K, Dudley J, Nei M, Kumar S. MEGA4: Molecular evolutionary genetics analysis (MEGA) software version 4.0. Mol Biol Evol 2007;24:1596-9. https://doi.org/10.1093/molbev/ msm092 
25.ISAG/FAO Standing Committee. Secondary guidelines for development of national farm animal genetic resources management plans. Measurement of Domestic Animal Diversity 2004; (MoDAD) Recommended Microsatellite Markers [cited 2017 Oct 27]. Available from: http://www.fao.org/3/a-aq569e. pdf

26. Thuy NTD, Melchinger-Wild E, Kuss AW, Cuong NV, Bartenschlager H, Geldermann H. Comparison of Vietnamese and European pig breeds using microsatellites. J Anim Sci 2006;84: 2601-8. https://doi.org/10.2527/jas.2005-641

27.Lemus-Flores C, Ulloa-Arvizu R, Ramos-Kuri M, Estrada FJ, Alonso RA. Genetic analysis of Mexican hairless pig populations. J Anim Sci 2001;79:3021-6. https://doi.org/10.2527/2001. $79123021 x$

28. Fabuel E, Barragan C, Silio L, Rodríguez MC, Toro MA. Analysis of genetic diversity and conservation priorities in Iberian pigs based on microsatellite markers. Heredity 2004;93:10413. https://doi.org/10.1038/sj.hdy.6800488

29.Li SJ, Yang SH, Zhao SH, et al. Genetic diversity analyses of 10 indigenous Chinese pig populations based on 20 microsatellites. J Anim Sci 2004;82:368-74. https://doi.org/10.2527/ 2004.822368x

30. Yang SL, Wang ZG, Liu B, et al. Genetic variation and relationships of eighteen Chinese indigenous pig breeds. Genet Sel Evol 2003;35:657-71. https://doi.org/10.1186/1297-9686$35-7-657$
31. Maudet C, Luikart G, Taberlet P. Genetic diversity and assignment tests among seven French cattle breeds based on microsatellite DNA analysis. J Anim Sci 2002;80:942-50. https:// doi.org/10.2527/2002.804942x

32. Nei M. Genetic distance between populations. Am Nat 1972; 106:283-92.

33.Laval G, Iannuccelli N, Legault C, et al. Genetic diversity of eleven European pig breeds. Genet Sel Evol 2000;32:187. https://doi.org/10.1186/1297-9686-32-2-187

34. Martinez AM, Delgado JV, Rodero A, Vega-Pla JL. Genetic structure of the Iberian pig breed using microsatellites. Anim Genet 2000;31:295-301. https://doi.org/10.1046/j.1365-2052. 2000.00645.x

35. Fan B, Wang ZG, Li YJ, et al. Genetic variation analysis within and among Chinese indigenous swine populations using microsatellite markers. Anim Genet 2002;33:422-7. https:// doi.org/10.1046/j.1365-2052.2002.00898.x

36. Nei M. Estimation of average heterozygosity and genetic distance from a small number of individuals. Genetics 1978;89: 583-90.

37. Kimloon $\mathrm{T}$. The specific nature and native pig raising at Huai Ngu sing village, Thung Hua Chang district, Lamphun province [MS. Thesis]. Chiangmai Thailand: Department of Animal Science, Faculty of Agriculture Chiangmai University; 1998.62 p. (in Thai). 